\title{
Constructive Simulation as a Collaborative Learning Tool in Education and Training of Crisis Staff
}

\author{
Goran Šimić \\ Military Academy, University of Defense, Belgrade, Serbia
}

\author{
gshimic@gmail.com
}

\begin{abstract}
This paper presents how military units and technology can help local societies in preparation for natural and man-made disasters by using constructive simulations. Contemporary constructive simulation systems allow for the implementation of non-combat scenarios, meaning that different social groups and institutions can be involved in learning exercises. These systems are recognized as tools appropriate for collaborative learning. Flooding scenario is used as a case study for the constructive simulation presented in this paper. Players are local community members and military personnel. They have to act as individuals - members of crisis staff and teams in rescuing and evacuating people, animals and material goods. Since flooding simulators are stand alone applications, specially designed for this purpose, dynamical hydrographical models have not been supported in constructive simulation systems. Therefore, in this work we have devised a new approach for simulating a flooding scenario. During the simulation, learners face many problems such as lack of resources and time on one hand and too many requirements on the other hand. Through an iterative process they learn and collaborate with each other and find appropriate solutions on how to perform their tasks. Different pedagogical strategies and tactics are used in accordance with the system constraints and opportunities.
\end{abstract}

Keywords: constructive simulations, collaborative learning, serious gaming, education and training

\section{Introduction}

Modern armies have significantly changed their missions during last decades. Help in natural and man-made disasters such as floods, earthquakes, fires, nuclear and chemical accidents and pollutions gained the importance. These complex tasks involve many organizations and social groups in affected areas: governmental and non-governmental institutions, emergency services, rescue teams, voluntary groups, and people from local communities. They have different skills and knowledge and use different procedures in operations. For their education, collaborative learning

Material published as part of this publication, either on-line or in print, is copyrighted by the Informing Science Institute. Permission to make digital or paper copy of part or all of these works for personal or classroom use is granted without fee provided that the copies are not made or distributed for profit or commercial advantage AND that copies 1) bear this notice in full and 2) give the full citation on the first page. It is permissible to abstract these works so long as credit is given. To copy in all other cases or to republish or to post on a server or to redistribute to lists requires specific permission and payment of a fee. Contact Publisher@,InformingScience.org to request redistribution permission. in joint teams with subject matter experts in constructive simulations is recognized as beneficial. The use of different exercise methods together with a novel pedagogical approach is needed for providing the desired learning outcomes. These are the issues the research presented in this paper dealt with.

Training in a real field and in real weather conditions is costly and timely. 
Resources are also available only to a limited extent. In addition, performing complex tasks requires a high level of skills and knowledge, which should be gained through practicing and repetition. However, real conditions do not allow for or make it almost impossible to repeat a simulation or its part. Therefore, educational goals are sometimes not fully met (Roman \& Brown, 2008). Computer simulations improve spatial learning and perceptual skills of learners (Lindgren \& Schwartz, 2009) and provide additional quality to learning process mainly based on textual and verbal interaction. Teachers have full control of a computer simulation. This means that they can start, stop, examine or restart a simulation at any time, which is not possible in a real situation (Holland, 1998). Simulation can be performed in a virtual environment, which allows for learners' high engagement. Interactivity, time constraints, and competitive nature motivate learners to use all their skills and knowledge in dealing with the concrete tasks and finding solutions for problems they are faced with.

There are different categorizations of simulation systems (Sulistio, Yeo, \& Buyya, 2004). In military training and education, there is a commonly used classification based on the complexity, used methodology and level of objectives (Hodson, 2009):

- Live simulations - realistic environment, soldiers and equipment, but without live ammunition;

- Virtual simulations - development of individual and/or team skills in complex virtual environments such as aircraft, battle ship, submarine and similar combat system simulators or urban area simulators designed for learning specific case-driven culture and language skills;

- Constructive simulations - the most complex and designed for training and education of staff and commanders of joint forces (e.g., brigade, division).

Joint forces means that officers from different branches and services (such as engineers, artillery, infantry, armored, reconnaissance, medical, transport, communication, and many other types) are involved in a simulation. In other words, there are several expert teams in many different domains that have to act as a whole. They need to learn from each other and to adapt their specific working procedures according to new tasks and organization. Constructive simulations are recognized in military environments as a way in which a complex training and education can be performed in effective (enriched quality) and efficient (cost reducing) manner.

During a simulation, teams of approximately 20 to 30 people face the problems given through a scenario. By analyzing the overall situation (spatial and time context, available resources, and critical targets), they try to find (alternative) solutions, evaluate them, and make decisions. Finally, they implement their decisions, track effects, and make changes and corrections in order to improve the results. All of the activities mentioned above represent the parts of the process of collaborative learning, performed through joint efforts of team members. They have to learn how to act together because they have their own priorities, procedures, and needs. They have to change their particular solutions, constrained by solutions of others, according to the general plan how to use resources in the most optimal way. Through constructive simulations they are becoming prepared for cooperation and collaborative work in real situations.

The content of this paper is divided into six sections. The next section gives an overview of related work in the areas of serious games and constructive simulations, their relationship and limitations of flooding simulation systems. The third section is about the methodology used in preparing of a concrete simulation. The actual constructive simulation with the flooding scenario is described in the fourth section. The achieved results and conclusions are represented in the last two sections. 


\section{Related Work}

Serious games represent mental contest, played using a computer in accordance with the game rules, and use entertainment for educational purposes and training (Zyda, 2005). Different from games primarily designed for entertainment, serious games have additional pedagogical functionality and allow teachers to adapt the game scenario according to the learning objectives. Constructive simulations have many common characteristics with serious games. Authors more focused on the technological aspects highlight the common way in which serious games and constructive simulations are built and structured. They recognize serious games and constructive simulations as two sub-domains within the training domain (Levesque et al., 2008). Others point out different characteristics that stem from differences between gamming and training preferences (Roman \& Brown, 2007). Whereas entertainment represents the main goal of games, in simulations it serves just as a motivational factor of the learning and training process.

Actual constructive simulation systems such as JCATS (USA) (Gauthier \& Kwinn, 2008), CAE's GESI - SIRA (Germany) (http://mst.texterity.com/mst/2009-2/?pg=34), or OTBSAF (Czech Republic) (Pavlů \& Vráb, 2007) offer a number of tools providing teachers and subject matter experts with full flexibility and scalability of simulation design: terrain, weather conditions, vegetation, natural and artificial objects and creatures can be created and adapted to the concrete scenario. For these reasons, different kinds of non-combat scenarios can be implemented (e.g., chemical and nuclear accidents and pollution, traffic accidents, and earthquakes). Regardless of advanced functionalities of these systems, they still do not support flooding scenarios.

There are several software systems designed for flooding simulation (Connell, Painter, \& Beffa, 2001). They are specialized for analysis and research purposes since they offer precise flooding dynamic data based on a geo-spatial system and a specific mathematical model (Yamaguchi \& Iwamura, 2007). These systems are focused on the prediction of flood dynamic depending on rainfall and spatial characteristic of a concrete terrain. Simulation of continually rising water levels needs a lot of processing power and memory usage as well as a large dataflow for visualization purposes (Ghazali \& Kamsin, 2008). Therefore, these stand alone applications are not designed for exchanging the data with the other systems such as constructive simulation software. Their precise flooding data can be used just in the preparation phase, for more detailed considerations and insights but not during a simulation.

Constructive simulations are intensively used in military organization for different purposes: education, training, research in military doctrine, validation and verification of new equipment, and many other purposes (Thorpe, 2010). High interactivity gives a new quality to the learning process. Learner's activities, procedures, behavior, and reactions are observed during a simulation (game); they are recorded and processed so they can be analyzed later (Michael \& Chen, 2006). The teacher can make conclusions about the learner's skills, specific knowledge and mental characteristics based on the information collected throughout the game (Kiili, 2005). That way he can focus his attention on the weakest characteristics of each individual and try to improve them. In addition, having information about how each individual has performed his part of the task makes it possible to create stronger and more coherent teams (Palazzi, Roccetti, \& Marfia, 2010).

The learning process in constructive simulations has a collaborative nature that can be considered in non-traditional way (Chee \& Hooi, 2002). Learners are typically adults with sufficient expert knowledge and experience in different domains, organized into joint staff and expert teams. They need to learn how to cooperate with each other, how to use resources of others and to give support to the others according to the specific problem given by the scenario and following the communication and cooperation procedures (Leemkuil, Jong, Hoog, \& Noor, 2003). They share the payoffs and outcomes; if the team wins or loses, everyone wins or loses (Zagal, Rick, \& Hsi, 2006). 
Constructive simulations are widely used in military education. They are built in the curricula of different courses such as military leadership (Mayrath \& O'Hare, 2009), cultural awareness (Allison \& Standley, 2010), tactical operations (Heinze et al., 2002), international security (McMaster, 2008), and many others in which learning of complex procedures in a collaborative manner is needed. Although the results reported in the literature confirm the usefulness of such systems (including the reduction of time and costs and a higher quality of education), there are certain problems, as well. During the preparation phase, building of a scenario, terrain, and forces lasts for weeks and sometimes even months and requires high engagement of teachers and subject matter experts (SME). During the execution phase, beside teachers and SME, lot of technical support staff is engaged, too. Their role is to provide stable and continuous execution of a simulation. Coordination of human resources and their long-term engagement, as well as insufficient preparation of exercises cause the main problems related to the constructive simulations.

Like games, constructive simulations should be attractive for players (learners). For this reason, the simulation's scenario should be understandable and realistic, adapted to the players' knowledge and skills, with clearly defined goals and objectives. If these requirements are not satisfied, learning goals will be missed.

\section{Methodology and Design of a Constructive Simulation}

This paper describes a case study of flooding by using constructive simulation as a tool for collaborative learning. As mentioned in the previous section, flooding simulation software is not applicable for this purpose because flowing water represents the only active content in its simulation. In contrast, constructive simulation software is not designed for the implementation of a flooding scenario, although it consists of powerful editing tools as well as tools for interacting with objects and living organisms in a synthesized environment. Continual rising of the water level is not supported in the contemporary constructive simulation software due to the discrete and static nature of the applied water model. In particular, water objects (as a set of data visualized in the map) represent a separate layer that is prepared in advance as the other map layers. Dynamic models implemented in flooding simulators are designed to produce permanent flooding data during a simulation. However, constructive simulators are not designed for the use of such data streams. The solution is found in discrete time modeling of rising water levels. It means that flooding data, obtained from a flooding simulation, are used for modeling of different layers of a constructive simulation map.

Since there is no dynamical data exchange between flooding and constructive simulation systems, different methods are used during the preparation phase:

- Observation of changes in the water level by using the flooding simulator on the specified terrain.

- Validation and verification of a new equipment entered into the constructive simulation system in the conditions of different water levels and stream velocity.

- Based on the observed water levels, the creation of different hydrographic layers for vector map used in the constructive simulation.

The preparation of the exercise is the longest and the most complex phase (Figure 1). By following the methods mentioned above, flooding data from official reports and flooding simulators are used for creating and modifying different entities: maps, equipment, and living organisms. After their creation, all of the entities need to be tested. 


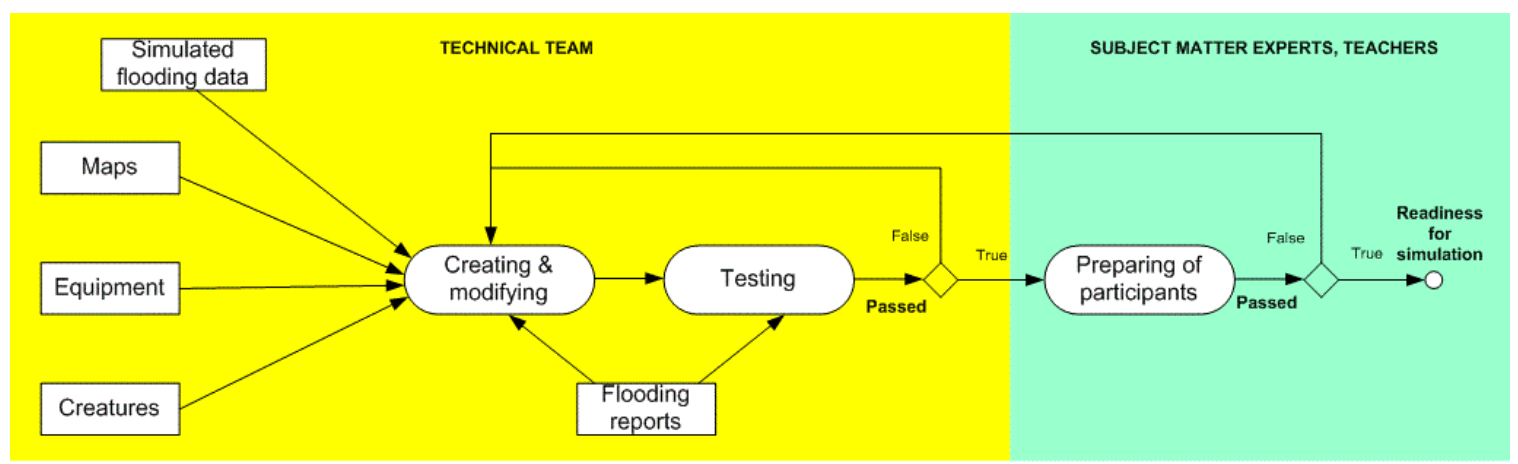

Figure 1: The methodology of the preparation phase

Beside the basic functions, such as movement of living organisms, vehicles, and boats, embarking and disembarking in different conditions of the terrain and water level, advanced tests were designed for fine-tuning the system. The official reports of flooding in the area of interest are included in them. They are important because of many particular events which occasionally happen (equipment failures, exhaustion of people and animals) but which could have a considerable influence on the order of actions during rescues and evacuations. The team for technical support is responsible for the mentioned activities.

Constructive simulation represents a well-structured activity in which all the participants play strictly defined roles. From an organizational point of view, participants can play several role types in a simulation: player, animator, director, and judge (technical support roles such as operator, administrator, and supervisor are out of scope and therefore they are aggregated with the technical team role). The Player role type is designed for learners. They can perform different kind of activities with the equipment, people, and animals assigned to them to be responsible for. Subject matter experts play the Animator role - they try to emulate real conditions and events according to the exercise scenario. Their actions animate the players to respond to the events and changes of the situation. Animators operate with the people, animals, and objects that need to be rescued and evacuated from endangered spots. During the exercise, they try to emulate the behavior of people and animals and to perform the movement of equipment and vehicles in a manner as realistic as possible. Official reports are also used for this purpose. One of the teachers plays the role of director. The director controls the overall situation, and he/she defines/changes the order of events according to the exercise goals and objectives. Other teachers (or subject matter experts) usually play the judge role - they observe and control the decisions and procedures of players during the exercise.

After reaching the technical readiness, teachers and the expert team can start preparing the players and animators separately. Teachers introduce the players to the terrain, the actual situation, and the available resources. At the same time, they assign concrete roles to the learners - mainly they play roles such as commander, chief, staff, and team members. Unlike in entertainment games, in constructive simulations roles (characters) are assigned deliberately. Finally, players and animators test the given resources. Their feedback is used by the technical team for further improving the simulation.

The organization of communication represents one of the most important parts of a constructive simulation. Collaborative learning needs to be structured for facilitating interaction between learners (Dillenbourg \& Fischer, 2007). There are different types of communication between players. Representatives of different organizations in joint teams (staff) communicate directly with each other. The communication with subordinates, cooperative and other supporting organizations is organized through networks by using voice communication and messaging (Figure 2). 


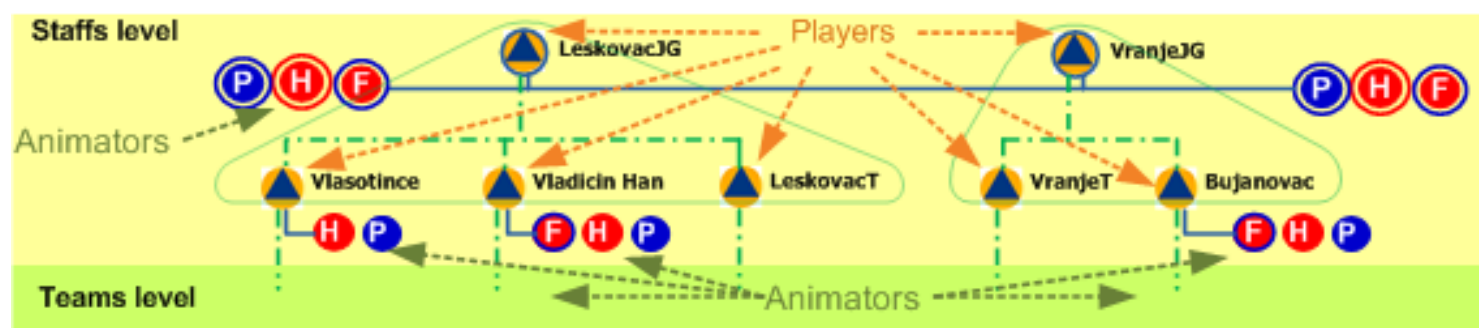

Figure 2: Organization of communication networks

There is the crisis staff, temporarily formed at the regional (joint group staff) and municipality level (staff), that exist until the elimination of the accident's consequences. There are also police, medical, and firefighting permanent staffs that the crisis staff cooperates with. This cooperation is done through peer to peer networks (full blue line connections on Figure 2) in which users (players and animators) communicate in a less formal way. There are subordination networks between crisis staff of different levels and with the concrete teams on the terrain (dash dot green line connections on Figure 2). Orders, commands and announcements are sent to the subordinates; requests and reports are sent in the opposite way. During dynamic activities these communication channels can be overloaded. Therefore the use of short formal messages is necessary. A part of the collaborative learning activities includes using standard procedures in voice communication and standard text messages. Through interaction, players learn how to use advantages of these procedures for obtaining appropriate resources as soon as possible.

After the preparation phase, the simulation can start. First, the Director presents the situation, available resources, and goals to the players. Different from most of entertainment games, constructive simulations are not leveled in the sense that satisfying one level is a prerequisite for moving to the next one. Simulation objectives are more complex and achievements can be evaluated only after the simulation analysis. Similar to the entertainment games, simulation becomes more dynamic over time (Ducheneaut, Yee, Nickell, \& Moore, 2007). Players analyze the problem, decompose it, and consider different ways for solving the problem. Through discussions they learn from each other. All of the staff members are involved in this collaborative activity. At the same time, they receive reports and requests from the subordinates. They need to react immediately: to find solutions, make decisions, and then provide resources and organize them according to the given tasks.

During the game, players perform various actions. Judges and the director observe them. Supervisors record all of the players' activities. If some action is irregular, the director can stop and repeat the exercise or its part. Methods used during a simulation are:

- Observing the players: how they cooperate with each other, how they make decisions, which actions they perform, how they follow the procedures and how they react to the sudden events.

- Tracking of communication: just few of players can communicate face to face; most of them need to use communication tools such a voice and messaging services; it enables measuring and analyzing of their collaborative activities.

- Coaching of situation according to the scenario and learning goals: temporary breaks in the simulation; during a pause the director and teachers can give suggestions and advice to the players; the simulation can be partially repeated or just continued.

- Making temporary breaks for invoking a new hydrographic layer. 
- Recording of the movements and activities on the ground: usually it is not possible to record all of the learners' actions due to the simulation's complexity; therefore, focus is on the main course of actions; decision about it is in the director's responsibility.

Besides the problem solving, role playing, brainstorming, discussing, peer learning, and writing of reports and orders, there are some additional pedagogical methods specific for constructive simulation. The preparation of the scenario includes defining the main course of actions and one or more alternatives (Figure 3). The main course is defined by the main objectives of the simulation. It consists of a sequence of activities which are expected to be performed by the players. Alternative courses are related to important events planned to happen during the simulation (changing of the water level, damage on some important road or bridge, the loss of communication links, etc.). Such events trigger alternative actions. Teachers are focused on them by measuring time of reaction, monitoring the effects of actions and controlling how players follow procedures.

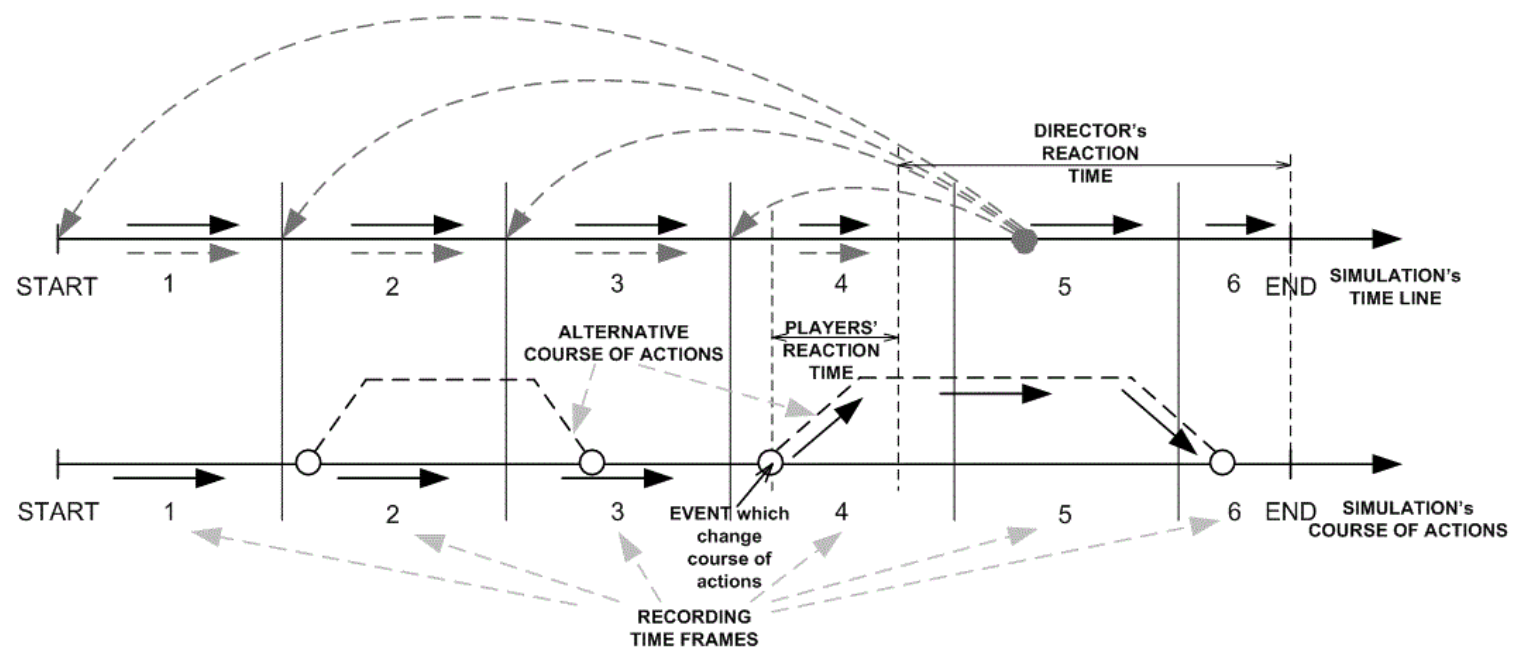

Figure 3: Simulation's time line and course of actions

If the reaction of the players is not satisfactory, the director can decide (usually together with the other teachers) to stop the simulation. It can be performed in any moment from the players' reaction to the end of the simulation (director's reaction time) and depends on the pedagogical goals which teachers want to achieve. They use this break for short reviewing of the achieved results and for giving instructions for further activities. From this point, the simulation can be continued or repeated partially or as a whole. Repeating of simulation parts is especially useful for players who do not have enough experience in collaborative work in complex environmental conditions.

The main course of actions is also important for determining the minimal duration of the whole simulation. For most of the actions and procedures, the execution time is known and the cumulative time can be calculated. For the learning purposes, players need more time than calculated in this way. From a technical point of view, the whole simulation is divided into time frames. At the end of each time frame the system makes a recording of the actual state of the simulation. These data are used for repeating purposes and for further analyses. The time frames are also used for making breaks for changing hydrographical layers in the map of terrain.

Constructive simulation ends by analyzing the results. This is also a part of the collaborative learning process. Through brainstorming based on recorded and statistically processed exercise data, the participants make conclusions about the exercise. The analysis methodology consists of four steps: 
- Firstly, the players present their reports about the achievement of the given tasks, difficulties and constraints they faced during the game; chiefs of staff are responsible for this step; players can present their own opinion about the new knowledge and experience they learnt as well as impressions about the simulation quality; this information is important for the technical team, teachers, and subject matter experts to make improvements in the scenario, maps, living beings, and equipment.

- In the next step, the technical team presents the facts based on the collected statistical data: number of rescued, evacuated, but also lost people, animals, and equipment; consumption of resources on activity basis (fuel, water, food, vehicles, boats); number and types of defects and injuries; the time needed for responding to events and requests; intensity of using communication equipment; this part of analysis ends with replaying fragments of exercise to point out some specific actions - good and bad examples.

- Teachers and subject matter experts (director, judges, animators) present conclusions in the last step: compared with previous presentations these are different because they have all the information about the scenario, events, flooding dynamic, deployment of living beings, equipment and objects on the terrain; they make a critical review of the whole simulation with the focus on collaborative work, following procedures, efficiency, and effectiveness.

It is not necessary to perform analysis immediately after the simulation. All of the participants need a time to prepare themselves for this activity. Over time attitudes become more objective. Immediately after the simulation, the participants are influenced by lot of subjective impressions. They have partial information and therefore they organize separate meetings with their teams and staff in order to make common conclusions about their work and results (Mercer, 2008).

\section{Case Study - Flood in the South Morava Region}

One of the most often natural or man-made disasters is flood. People, animals, and material resources have to be rescued from the dangerous area as quickly as possible. It is easy to say but

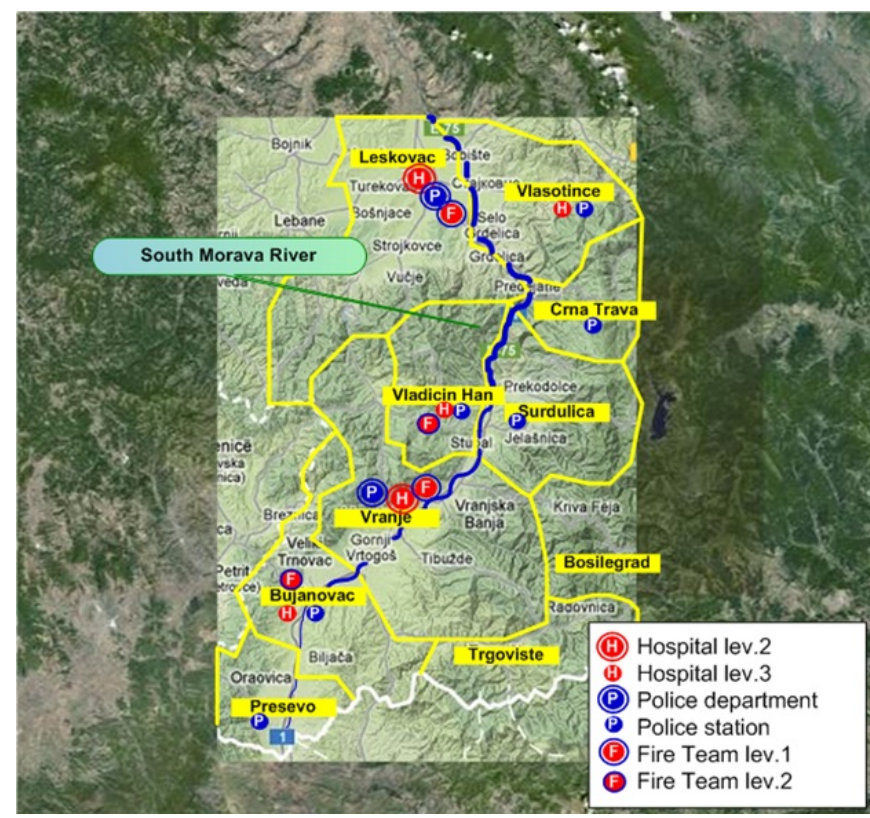

Figure 4: Municipalities of South Morava valley (region of south Serbia, Europe) very hard to do because of the lack of time, transportation means, trained people, and communications. The case study presented in this section demonstrates models and pedagogical strategies and tactics that improve team work between different social and institutional structures in a new and interesting way.

The South Morava valley (Figure 4) represents one of the Serbian regions which are highly exposed to flooding. This small area $(60 \mathrm{~km}$ long in South - North direction and $40 \mathrm{~km}$ wide in East - West direction) is very complex in many ways. The valley consists of several fields separated by gorges. The South Morava River is neither that big nor long but it is surrounded by high 
mountains covered with a lot of snow during the winter. When melting, snow is often combined with lots of spring showers. That results in the flooding of this area; especially in the narrow gorges that act like bottle necks.

At the same time, this valley is one of the most important traffic corridors. It connects south and east parts of Europe with the rest of the Europe. The valley is divided in 10 municipalities. As a whole, they have considerable human and technical resources to protect themselves from floods but as individual communities they are vulnerable to this kind of disaster. Municipalities on the north are more affected than southern ones. All of them have local police stations, civil protection units, and local health centers. Several companies have facilities in this region. They are also interested in protecting themselves of floods.

The main problem is how to prepare these heterogeneous organizations to act as one in the protection from floods. The first exercises were performed without the use of simulation software. The teams were trained by using paper maps, simple scenarios, and communication equipment. The exercise results always satisfied the local government. Unfortunately, experience has shown that exercise results were poorly correlated with the results in the reality. The main characteristic of local community organizations is that they are well trained to act on the local terrain, commanded by the local government structure formed for specific situation. The problem is they have never acted as a part of bigger joint groups under the same command and coordination. Therefore, people need to learn to collaborate with each other in some other more attractive and more objective way. This was the main motive for including constructive simulations.

\section{Simulation Scenario}

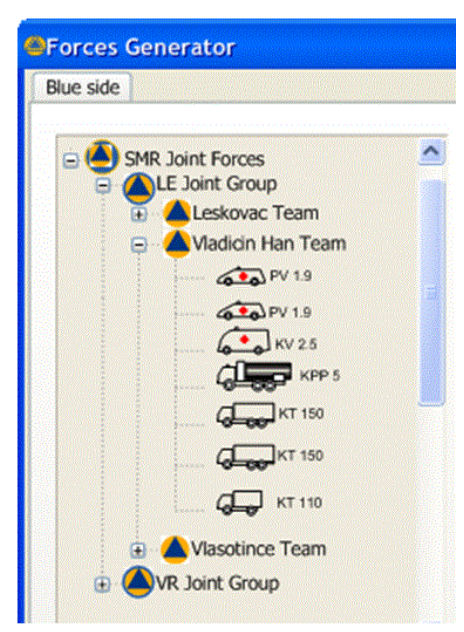

Figure 5: Units - organization \& equipment
Organizational similarity between military units and nonmilitary organizations such as police, medical teams, and firefighting units was used for building the scenario (Figure 5). Constructive simulation software JANUS - France, version 10 was used as a platform for simulation (Khimeche \& Champs, 2004). It provides a palette of tools for editing of maps, objects, living organisms, and equipment. Beside the simulation engine and simulation client applications, it consists of analysis tools which allow for statistical processing of the data recorded during the simulation, replaying of the actions, communication recording, and statistics.

In this case study all of the resources are represented in the system as one unit named South Morava Region (SMR) Joint Forces. It consists of two subunits, joint subgroups dependent on the position: southern Vranje ( $V R J G$ ) and northern Leskovac $(L E J G)$. These two subgroups are under command of joint staff and they have local staff under subordination.

As explained in the previous section, the staff cooperates with local institutions and they command the local teams.

The scenario includes flooding produced by insufficient throughput under the bridge in the case of rapid increasing in the quantity of water (Figure 6). Changing of the water levels are emulated by changing of different hydrographical layers previously prepared. Simulation is split into several time frames. It means instead of permanent water rising or declining, there are temporary breaks according to the scenario. During the pause, the technical team changes the layer. In these conditions the learners have to make predictions about spreading of the affected zone and to take care about the locations where people, animals and equipment are. During the breaks, time meas- 


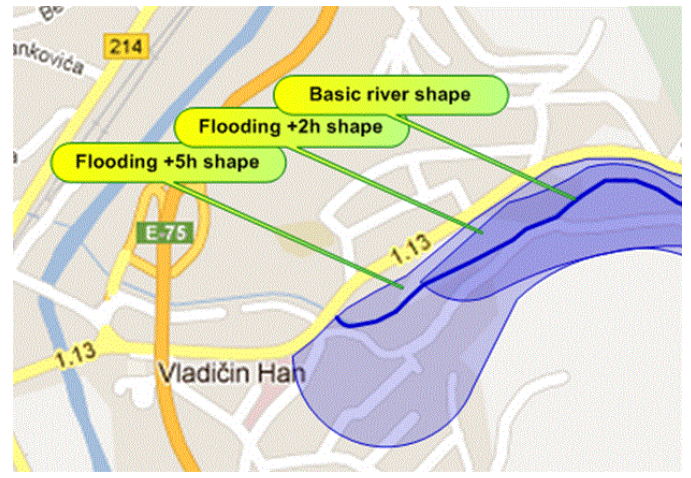

Figure 6: Flooding emulation in constructive simulation exercise uring is also stopped to avoid influence of the system constraints on the final exercise results. Since the flood happens in the urban area (Vladicin Han), players face other problems: movement is limited on the streets and roads, there are lot of endangered people and animals, the available time is short, and human and technical resources are limited and they are not in place to use.

\section{Gaming}

After the game begins, the players start their collaborative work on analyzing the situation, evaluating the resources, and finding solutions. After making decisions they carry them out through the orders, reports, and other types of formal and informal messages. They can make movements, embark and disembark people, animals, and means. All of the entities the players can interact with (e.g., vehicles, boats, people, and animals) are represented by so called pions - symbols used for their representation on the map. The pions can be aggregated and disaggregated (Figure 7).

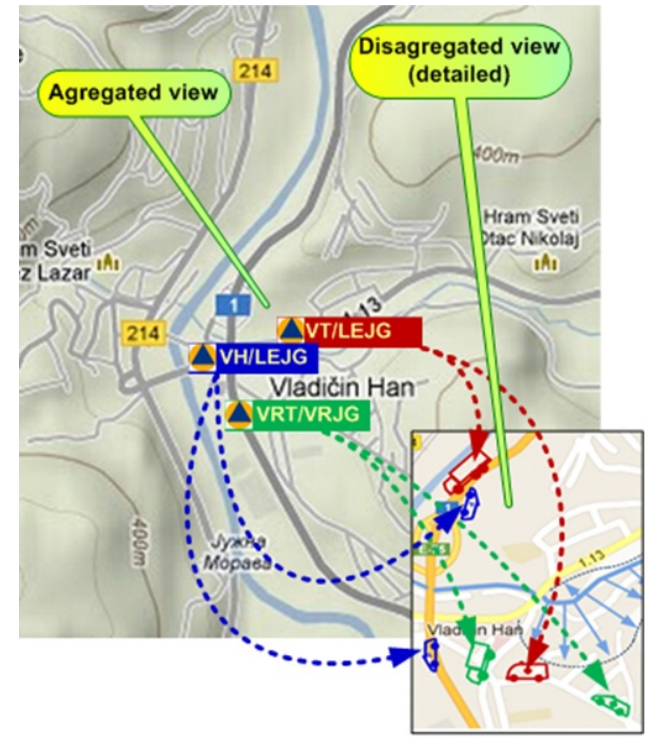

Figure 7: Aggregated and disaggregated views during the game
For example, the whole team, or group can be presented with one (aggregated) pion (e.g., VH/LEJG represents a group in Vladicin Han that belongs to Leskovac joint group). This is a usual situation when the map is zoomed out and many people and equipment are represented on it. Then operators can aggregate pions to provide clear view on the map. The pions need to be disaggregated if a player wishes to perform a concrete action with it (e.g., rescuing, evacuation, transportation, protection of properties, and blocking unsafe roads and zones). A disaggregated pion is represented with its own icon and in the same color as the unit it belongs to.

During the simulation, the functional ability of the equipment is changeable depending on different reasons (e.g., motor failure, lack of fuel, impassable terrain). The percentages of failures and weakness of people and animals are in accordance with the scenario. These numerical data are entered in the preparation phase. The stochastic model im-

plemented in the simulation engine determines when and where these events will occur. For players these events are unpredictable. For this reason, they need to communicate with each other verbally or by sending and receiving different types of messages and documents such as orders, commands, requests, reports, and information about the situation and events. Players also learn how to manage and use lot of information by using regular document templates and additional tools such as spreadsheets and time tables. 


\section{Analysis}

The last phase of the exercise is analysis (so called AAA - Analysis After Actions). The technical team extracts recorded data and tries to interpret and visualize them together with teachers. Lots of different quantitative data are included: fuel consumption, number of rescued and evacuated, losses, defects, useful and useless actions, and others. This way the conclusions, such as dissemination and exchange of information or following of standard procedures, are based on measured results and facts. The influence of subjective estimations and attitudes is minimized. Finally, several meetings are organized for different purposes (details are described in the section on methodology and design). All of the aggregation levels - individual, team and joint group level - are covered by the analysis.

During the simulation, communication activities are recorded. These data are also included in the analysis. How much players used the communication equipment, did they use it in a proper way, how is communication intensity related to the occurrence of events and implementation of activities represent some of the questions the participants try to answer during the analysis. Different types of diagrams are useful for this purpose (Figure 8).

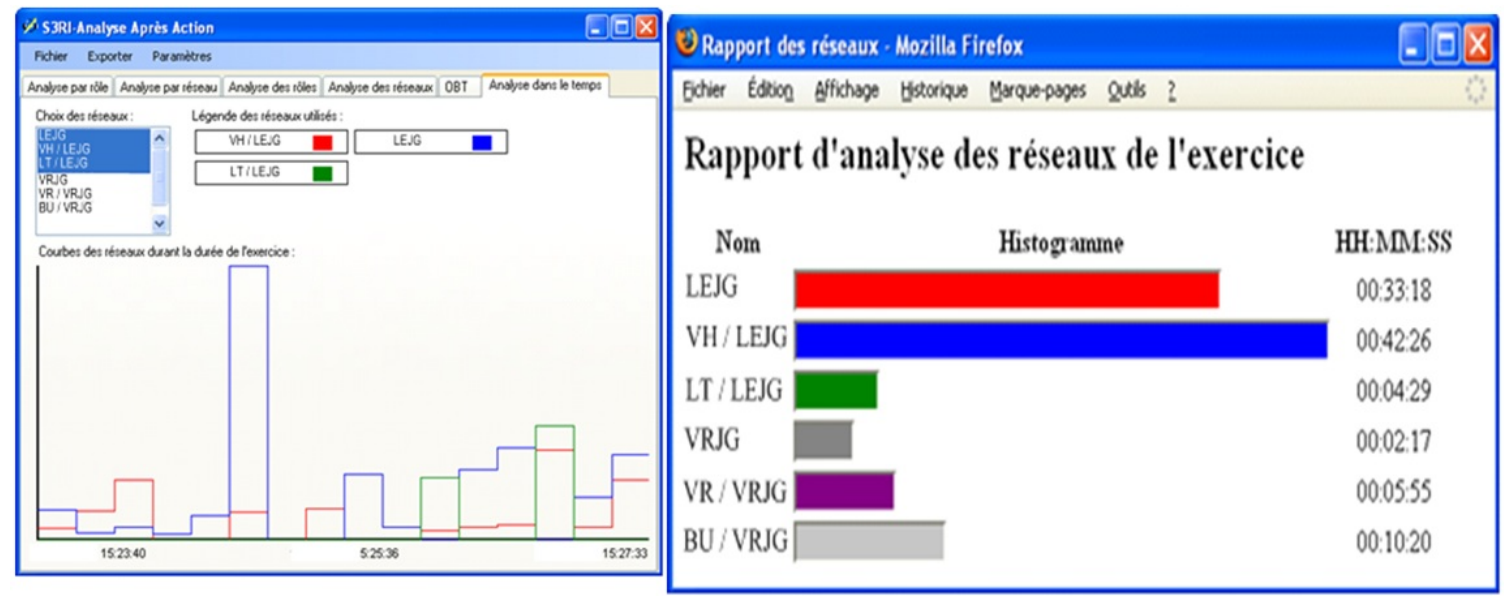

Figure 8: Different types of diagrams used for analyzing of communication activities

Time based diagrams (on the left hand side of Figure 8) are used for analyzing communication between groups (staff) over time. Teachers can correlate communications between different groups by selecting them from the list. Knowing the times of activities and events during the simulation, they can also correlate communications with them. Cumulative time histograms (on the right hand side of Figure 8) are used for overall activity reports. They show differences in the use of communication network between particular groups.

The analysis tool offers many other types of diagrams for data visualization. They are used for the interpretation of the course of actions correlated with events such as changing of the water level, damages on infrastructure objects, and defects of equipment. Teachers, subject matter experts, and learners together participate in making conclusions because every separate simulation, even with the same scenario, is different. Everybody can learn something new and get the new experience.

\section{Results and Evaluation}

The evaluation brings a comparison of the results of teams trained with and without the use of constructive simulations. The scenario used in simulation is based on a detailed analysis of a real flooding in the South Morava valley. This way the evaluation can be considered as proper experiment with the experimental and control group. The scenario is built on empirical data. Nearly the 
same number of people and means (as in the real flooding) were involved in it. The effects of the rise of the water level (described in Gaming section) are adapted to the ones found in official reports. Owing to this, the conditions for the evaluation of simulation are provided.

Metrics used in the evaluation include the results achieved in exercise (SIMEX) and data collected from official reports (SITREP). They are compared with each other. Various comparison criteria are used. The most important one is about how many people, means and animals are rescued and evacuated from the affected area (as the main effectiveness criterion). The compared results are presented in the chart given on Figure 9. Beside the data from official reports (SITREP) there are three data sets (SIMEX 1/1 - 3). In the manner described above (in the Gaming section), the director stopped the exercise two times. The first time it was due to the lack of communication between the participants and the wrong decision about the direction of evacuation. The reason for the second stop was the lack of coordination between teams for ground and water evacuation:

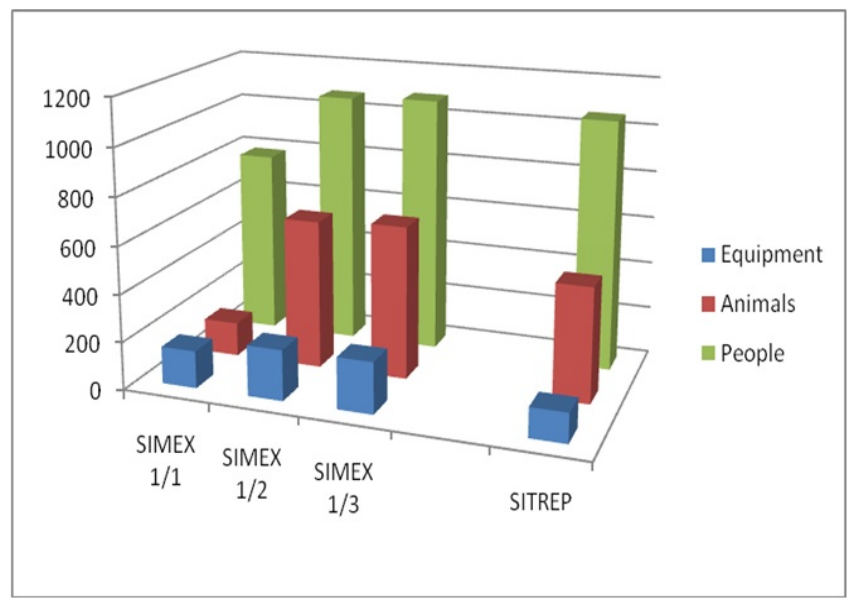

Figure 9: Comparison in "Rescued and evacuated" there was a lot of waiting time between disembarking from the boats and embarking in transport vehicles. For pedagogical reasons, in both cases, the director stopped the simulation immediately before it ended. This way the teachers had enough time for making notes and collecting data about the players' actions. The reason for this type of coaching is that the players are professionals with lot of experience in disaster recovery but they never worked together in such a way. The director needed convincing arguments for decision such as repeating of simulation parts in order to keep the players motivated.

Data set labeled as SIMEX 1/3 represents the final simulation result. Other two sets represent the results of the first and second attempt. The main progress was achieved in the rescuing of people and animals during the second attempt (SIMEX 1/2) regardless of the last attempt best results. The final result shows minor difference in the number of rescued people (rescued 15 persons more than recorded in SITREP of real flooding) while the results of rescuing and evacuation of equipment and animals are significantly improved than those in the SITREP ( $70 \%$ more animals and $\sim 30 \%$ more equipment).

After the detailed analysis of SITREPS it is concluded that the major problem in the case of the real flooding was in the organization of evacuation: most of the tasks were solved sequentially and due to the highest priority of people rescuing, the most of animals and means were neglected and left uncared for. Based on the simulation's final results, it can be expected that this problem is solved. Players have learnt how to collaborate with each other in performing actions simultaneously and how to use resources in more efficient and effective way. A survey conducted with 24 participants after the simulation uncovered some interesting facts:

- Most of the players had experience in IT technology, and an ECDL license (European Computer Driving License, www.ecdl.org); they have used games for entertainment, and Internet-based tools for social communication such as Facebook, LinkedIn or Twitter $(78 \%)$. 
- None of them had any experience in using any kind of constructive simulation while some of them ( $9 \%$ ) have used flying and driving simulators (mainly for entertainment).

- Most of them ( $95 \%)$ are satisfied with the simulation, especially with its high interactivity, the use of digital (vector) maps and communication tools.

- The majority of remarks are related to:

○ Scenario (23\%) - it is more complex than they expected before the exercise; the players recognized as the main problem the sudden changes in the water level and the lack of time for preparing and performing the corresponding actions.

○ Repeating of parts of the simulation (41\%) - they agreed that the breaks have been useful for them because of the teacher's suggestions, recommendations, and help. In contrast, they criticized the way in which the simulation was repeated; from their point of view it would have been better to make breaks immediately after the occurrence of errors and omissions than at the end of simulation.

- Difficulties in using voice communication (11\%) - there were several (VoIP) networks established for providing voice and data communication between staff members; the players were confused with the use of call signs and changing communication channels between the networks.

This feedback reflects the profile of the players: they are younger people ( 23 - 45 years old), well skilled in IT and without any experience in constructive simulations. Therefore their remarks are reasonable and mainly objective. They faced significant changes in the flooded area caused by the changing water level. They became adapted to it during the second and the third attempts regardless of their attitudes towards the repetition of the simulation. Difficulties in voice-over-IP communication are explained by detailed analysis of the communication records. They were caused by a misunderstanding of the organization of the networks: in attempting to communicate with subordinates, superiors or cooperators, the players often forgot to switch the channel before; the effect of misunderstanding was also produced by using both of players' call signs and real names in the calling procedure.

\section{Conclusion}

This paper presents a case study in using constructive simulation software, originally designed for military purpose, in education and training of civilian protection staff and teams. A flooding scenario based on a real flooding case is used in the study. Different from other disasters, flooding has well defined time frame which enables teams to deal with it. On the other hand, rapid rise in water level and shape forces players to make priorities, as well as to make and change decisions quickly. Moreover, they need to collaborate with each other directly (if they belong to the same team) or indirectly (by using tools for voice communication and data exchange). Rescuing and evacuation of people, animals, and properties from endangered area represent the common goal for players. They learn by solving many particular problems and performing many activities to achieve this goal.

The presented simulation is recognized as a tool as well as a pedagogical strategy appropriate for collaborative learning. Complex conditions cannot be simulated without powerful software tools. In contrast, flooding simulators are not designed for such a collaborative work. The solution is found in using of constructive simulation software in a new way:

- Changing of water level is emulated by using multiple hydrographical layers in the map of the terrain.

- Data from official flooding reports are used in building the scenario. 
- A new type of coaching is applied during the simulation; it provided enough time for layers changing, learners' reactions on events, and teachers' reactions on performed activities

- Communication networks are organized in accordance with the collaborative learning needs.

- Since the scenario was almost the same as the real flooding case, the simulation is considered as a proper experiment and its results are evaluated by comparing its results with the data collected from the real flooding reports.

The exercises performed without such software lack reality and interactivity. Regardless of the presence of well skilled individuals, they produce unsatisfactory results when acting as team(s). This is reflected in the waste of resources during real rescuing and evacuation.

Another reason for using simulation exercise is that the corresponding real situation is much more stressful; people cannot repeat their actions or correct their mistakes. Simulation presented in the paper shows its iterative nature which is required for repeating of actions in order for learners to get used to severe and stressful situations. The advantage of a simulation exercise is that the learners' knowledge and skills can be improved in safe conditions. That way they tend to be calmer and more concentrated on their tasks in real situations.

Final analysis indicates another pedagogical advantage of constructive simulations. During the simulation all of the data are recorded. These data are processed and visualized in order to perform analysis and make conclusions. All of the participants are involved in this process. Without the final analysis the simulation would be just a competitive serious game designed for improving basic skills. The presented reviews and conclusions made by learners and teachers together represent the important part of the learning process. They help in acquiring new knowledge and experience. It is not only about learning, but also about learners changing their attitudes towards the importance of collaborative work and about knowing of opportunities of others in giving help and support. In real situations the lack of such knowledge can lead to decision making mistakes and performing actions in a wrong way. The performed evaluation shows the usefulness of constructive simulation exercises in education and training of organizational structures used in natural or men-made disasters.

\section{References}

Allison, A., \& Standley, M. H. (2010). The cultural imperative for professional military education and leader development. U.S. Army War College. Retrieved on August 28, 2012 from http://www.dtic.mil/cgi-bin/GetTRDoc?Location=U2\&doc=GetTRDoc.pdf\&AD=ADA514735

Chee, Y. S., \& Hooi, C. M. (2002). C-VISions: Socialized learning through collaborative, virtual, interactive simulations. Proceedings of the Conference on Computer Support for Collaborative Learning: Foundations for a CSCL Community, 687-696.

Connell, R. J., Painter, D. J., \& Beffa, C. (2001). Two-dimensional flood plain flow. II: Model Validation, Journal of Hydrologic Engineering, 6(5), 406-415.

Dillenbourg, P., \& Fischer, F. (2007). Basics of computer-supported collaborative learning. Zeitschrift für Berufs- und Wirtschaftspädagogik, 21, 111-130.

Ducheneaut, N., Yee, N., Nickell, E., \& Moore, R. J. (2007). "Alone together?" Exploring the social dynamics of massively multiplayer online games. Proceedings of the SIGCHI Conference on Human Factors in Computing Systems, ACM, 407-416.

Gauthier, S., \& Kwinn, M. (2008). Thunder Run in the classroom. Proceedings of the 2008 Spring Simulation Multiconference (SpringSim '08), 805-810. 
Ghazali, J., \& Kamsin, A. (2008). A real time simulation and modeling of flood hazard. Proceedings of 12th WSEAS International Conference on SYSTEMS, 438 - 443.

Heinze, C., Goss, S., Josefsson, T., Bennett, K., Waugh, S., Lloyd, I., ... Oldfield, J. (2002). Interchanging agents and humans in military simulation. AI Magazine, 23(2), 37 - 47.

Hodson, D. (2009). Performance analysis of live-virtual-constructive and distributed virtual simulations: Defining requirements in terms of temporal consistency. Doctoral dissertation, Air Force Institute of Technology Wright Patterson AFB, OH, ISBN: 978-1-109-52283-9

Holland, J. (1998). Emergence: From chaos to order. Redwood City, California: Addison-Wesley.

Khimeche, L., \& Champs, P. (2004). Aide à la planification d'engagement tactique terrestre: M\&S in decision support for course of action analysis, APLET. Retrieved on August 28, 2012 from http://ftp.rta.nato.int/public//PubFullText/RTO/MP/RTO-MP-MSG-028//MP-MSG-028-04.pdf

Kiili, K. (2005). Digital game-based learning: Towards an experiential gaming model. Internet and Higher Education, 8(1), 12-24.

Leemkuil, H., Jong, T., Hoog, R., \& Noor, C. (2003). KM QUEST: A collaborative Internet-based simulation game. Simulation and Gaming, 34(1), 89-111.

Levesque, J., Cazzolato, F., Perron, J., Hogan, J., Garneau, T., \& Moulin, B. (2008). CAMiCS: Civilian activity modelling in constructive simulation. Proceedings of the 2008 Spring Simulation Multiconference (SpringSim '08), 739-744.

Lindgren, R., \& Schwartz, D. L. (2009). Spatial learning and computer simulations in science. International Journal of Science Education, 31(3), 419-438.

Mayrath, M. C., \& O'Hare, S. M. B. (2009). A proposed method for converting squadron officer school into a blended-learning course with live, virtual, and constructive simulations. Study from Institute for Advanced Technology - The University of Texas at Austin. Retrieved on August 28, 2012 from http://www.aetc.af.mil/shared/media/document/afd-090320-051.pdf

McMaster, H. R. (2008). On war: Lessons to be learned. Survival: Global Politics and Strategy, 50(1), 1930 .

Mercer, N. (2008). The seeds of time: Why classroom dialogue needs a temporal analysis. Journal of the Learning Sciences, 17(1), 33-59.

Michael, D., \& Chen, S. (2006). Serious games: Games that educate, train, and inform. Boston, MA: Thomson Course Technology.

Palazzi, C. E., Roccetti, M., \& Marfia, G. (2010). Realizing the unexploited potential of games on serious challenges. Computers in Entertainment (CIE), 8(4), 1-4.

Pavlů, P., \& Vráb, V. (2007). Interconnection OTBSAF and NS-2. In Improving M\&S Interoperability, Reuse and Efficiency in Support of Current and Future Forces (pp. 19-1 - 19-6). Meeting Proceedings RTO-MP-MSG-056, paper 19. Retrieved on August 28, 2012 from http://ftp.rta.nato.int/public//PubFullText/RTO/MP/RTO-MP-MSG-056///MP-MSG-056-19.pdf

Roman, P., \& Brown, D. (2007). Constructive simulation versus serious games: A Canadian case study. Proceedings of the 2007 Spring Simulation Multiconference (SpringSim '07) - Volume 3, pp. 217-224.

Roman, P., \& Brown, D. (2008). Games - Just how serious are they? Interservice/Industry Training, Simulation, and Education Conference (I/ITSEC 2008), Paper No. 8013, Retrieved on March 5, 2012, from http://www.vbs2.co.za/images/Games_How_Serious_Paper.pdf

Sulistio, A., Yeo, C. S., \& Buyya, R. (2004). A taxonomy of computer-based simulations and its mapping to parallel and distributed systems simulation tools. Software: Practice and Experience, 34(7), 653673. 
Thorpe, J. (2010). Trends in modeling, simulation, gaming: Personal observations about the past thirty years and speculation about the next ten. Proceedings of Interservice/Industry Training, Simulation, and Education Conference (I/ITSEC) 2010, Paper No. IF1001

Yamaguchi, S., \& Iwamura, K. (2007). Fast flood simulation method using dynamic DDM. IPSJ Transactions on Mathematical Modeling and Applications, 48(6), 92-103.

Zagal, J., Rick, J., \& Hsi, I. (2006). Collaborative games: Lessons learned from board games. Simulation \& Gaming, 37(1), 24-40.

Zyda, M. (2005). From visual simulation to virtual reality to games. IEEE Computer, 38(9), 25-32.

\section{Biography}

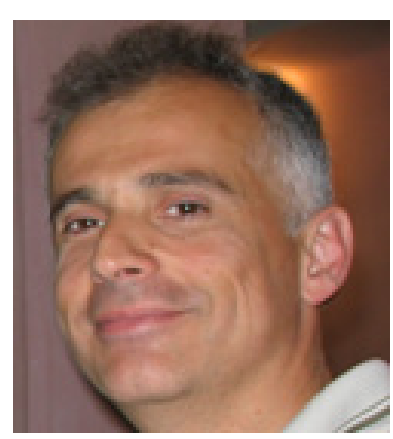

Goran Šimić, PhD, is the Director of the Center for Simulations and Distance Learning, Military Academy, University of Defense, Belgrade, Serbia (http://www.va.mod.gov.rs/cms/view.php?id=21662). Goran is also an Assistant Professor of Computer Science specialized in expert systems, object-oriented design and implementation, and business software applications. His current research interests are in the area of interoperability between different learning resources \& systems, and their integration with diverse types of Web services and applications. So far, he has authored/co-authored about 20 research papers and made contributions to three books. He is a member of the GOODOLDAI research network (http://www.goodoldai.org/goran_simic). 